\title{
EXPERIMENTAL \& NUMERICAL STUDY OF FORCED CONVECTION LAMINAR FLOW THROUGH COPPER MICRO CHANNEL HEATSINK
}

\author{
S.Subramanian ${ }^{1}$, K.S.Sridhar ${ }^{2}$, C.K.Umesh ${ }^{3}$ \\ ${ }^{1}$ Microwavetube Research \& Development center, Jalahalli, Bangalore, India \\ ${ }^{2}$ PESIT, 100 feet Ring Road, BSK III Stage, Bangalore, India \\ ${ }^{3}$ University visvesvaraya college of engineering, KR Circle, Bangalore, India
}

\begin{abstract}
A rectangular micro channels having 500 microns width \& 1500 microns depth have been machined out of Oxygen free high conductivity Copper material on an area of $12.5 \mathrm{~mm} X 25 \mathrm{~mm}$. De-ionized water was used as a coolant. The thermal \& fluid flow performances have been tested for the flow velocities ranging from $0.5 \mathrm{~m} / \mathrm{s}$ to $1.2 \mathrm{~m} / \mathrm{s}$. Micro channels performances have been numerically simulated using commercially available computational fluid dynamics software ANSYS CFX. The simulated results have been validated with the experimental results and published literature. The effects of Temperature dependent material properties on simulation have been examined.
\end{abstract}

Keywords: Metallic micro channels, Single phase laminar flow cooling, Thermal performance of micro channels, Electronics cooling

\section{INTRODUCTION}

Metallic micro channels are widely opted due to its mechanical robustness and the higher value of heat transfer coefficient per unit coolant flow. Thermally high conductive materials such as silicon, aluminium \& copper are generally preferred for the manufacture of metallic micro channels. Initially, the works of D.B Tuckerman \& R.F.W Pease[1] brought the attraction on silicon substrate based micro channels. They had achieved a thermal resistance of $0.09^{\circ}$ $\mathrm{C} / \mathrm{W}$ over one $\mathrm{cm}^{2}$ area and had tested upto $790 \mathrm{~W} / \mathrm{cm}^{2}$. The substrate temperature rise was $71^{\circ} \mathrm{C}$ above water inlet temperature. Various manufacturing processes like LIGA, Chemical etching, Stereo lithography, Micromachining \& Diffusion bonding had been reported to be suitable for micro channel fabrication by Sean Asman et al [2]. Fabrication and testing of a micro channel cooling plate which is meant for microelectronic packaging cooling applications have been described by A. J. Pang', M.P.Y. Desmulliez et al [3]. The nickel-based micro-channel cooling plate was fabricated on a glass substrate using a two-layer electroforming process borrowed from the UV-LIGA process. Forced convection of air was used for the micro channel plate. The cooling plate was tested using a custommade rig to measure the pressure head as a function of mass flow rate.

Eason et al 2004 [4] investigated various manufacturing methods for micro channels fabrication, such as wet $\&$ dry etching in silicon, as well as precision mechanical sawing in silicon \& thermo-set plastic. They described the experimental methods used for measuring the pressure flow characteristics of the manufactured channels. Both analytical [6-8] and numerical [9] methods were frequently used for the investigation of micro channels. A novel integral micro-channel heat sink was fabricated, directly on the back-metallization layer of copper brazed with ceramic substrate of the semiconductor junction by Fanghua Mei et al,[10]. Lijubisa D stevanovic et al,[11] reported that the micro channels manufactured by micro milling techniques performed better than laser ablated samples due to dimensional distortion. Ngotan Tran et al,[12] manufactured a rectangular cross section micro channel having $500 \mu \mathrm{m}$ width and $210 \mu \mathrm{m}$ depth using micro machining techniques. The heat sink was tested using water as coolant for the mass flow rates varying from 0.2 to $0.4 \mathrm{~g} / \mathrm{s}$. The pressure drop was reported to vary from 1761 to $4184 \mathrm{~Pa}$.

Generalized correlation [13] for predicting nusslets number in the thermally developing region has been developed using three dimensional numerical simulation. Temperature dependent material property models [14] have been used for three dimensional numerical simulation of oblique \& plate fin types of micro channel heat sinks. The micro channels were cut on copper and were tested for the flow with Reynolds number ranging from 400 to 800 . The simulated resulted have been validated with experimental results. Particularly the use of copper helps in spreading the heat uniformly around the micro channel, closely approximating the theoretical assumptions. Hence it is pertinent to study the copper based micro channels as it has potential use in electronics cooling. In this paper the thermal \& fluid flow performance of copper based micro channel heat sink with a hydraulic diameter of $0.75 \mathrm{~mm}$ have been studied numerically \& experimentally. Experimental tests were performed for different flow rates where the reynolds number varied from 503 to 1197 . The results were compared with the published data. The results of the simulation using the temperature dependent material properties are also presented. 


\section{EXPERIMENTATION}

Experimental setup consisted of reservoir, micro pump, power supplies, heater, pressure gages, thermocouples, data acquisition, micro channel heat sink etc,. Plate fin type of micro channels have been machined out of OFHC (Oxygen free High conductivity) Copper on an area of $12.5 \mathrm{mmX} 25 \mathrm{~mm}$ using micro milling technique as shown in figure 1 . The heat sink consisted of 12 fins with 500 microns width and 1500microns depth. De-Ionized water has been used as coolant.

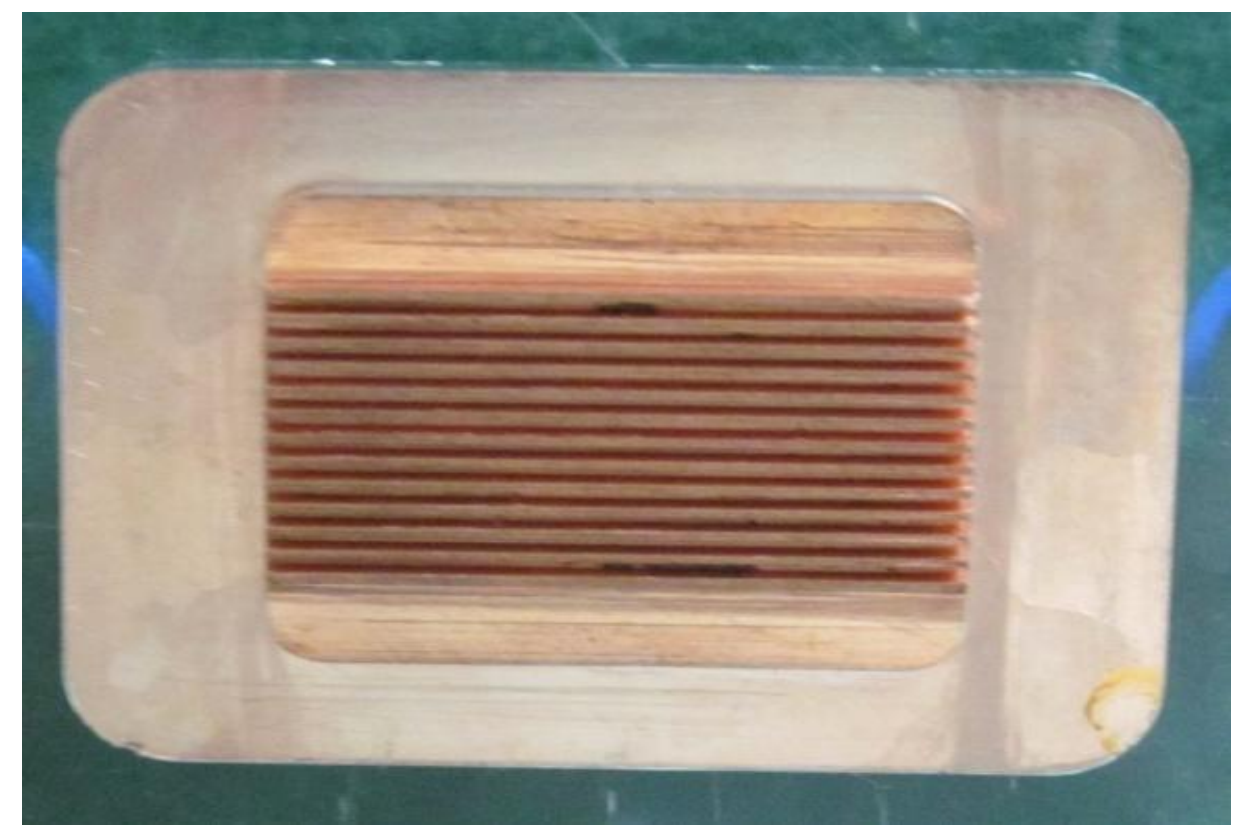

Fig 1: OFHC copper microchannels

A heater of 100W capacity has been attached on the rear side of the micro channel heat sink. The micro channel heat sink was housed inside a Perspex enclosure as shown in figure 2. The Perspex enclosure acts as a insulator for heat loss from the heater so that maximum heat flows to the fluid through the micro channels. The cross section of the coolant passage at the inlet $\&$ outlet passage was $12.5 \mathrm{~mm}$ wide to a depth of $1.5 \mathrm{~mm}$. Submersible water pump has been used for pumping the coolant to the micro channel heat sink from the tank through a 20microns filter. Access holes have been drilled on the perspex for thermocouple \& pressure gages. The experiment has been carried out in a controlled atmosphere.

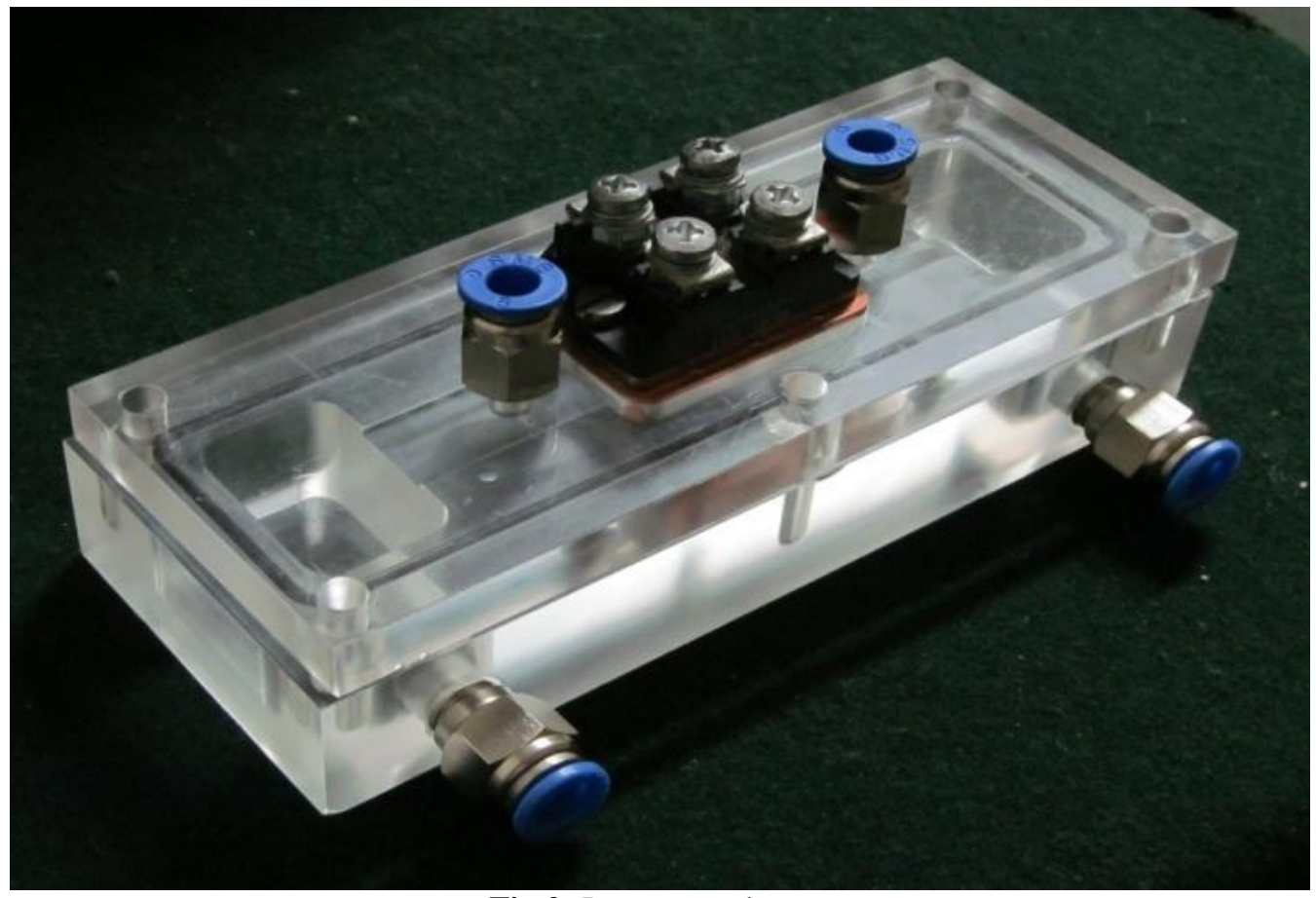

Fig 2: Perspex enclosure 
The pressure drop across the micro channel heat sink was monitored using differential pressure gage. Five different thermocouples of $\mathrm{J}$ type have been used in the experiment. Two of them were used to measure the micro channel heat sink temperature, another two of them were used to measure temperature of inlet, outlet water temperature and the remaining one was used to measure ambient temperature. The schematic sketch of the experimental setup used for testing is shown in figure 3.

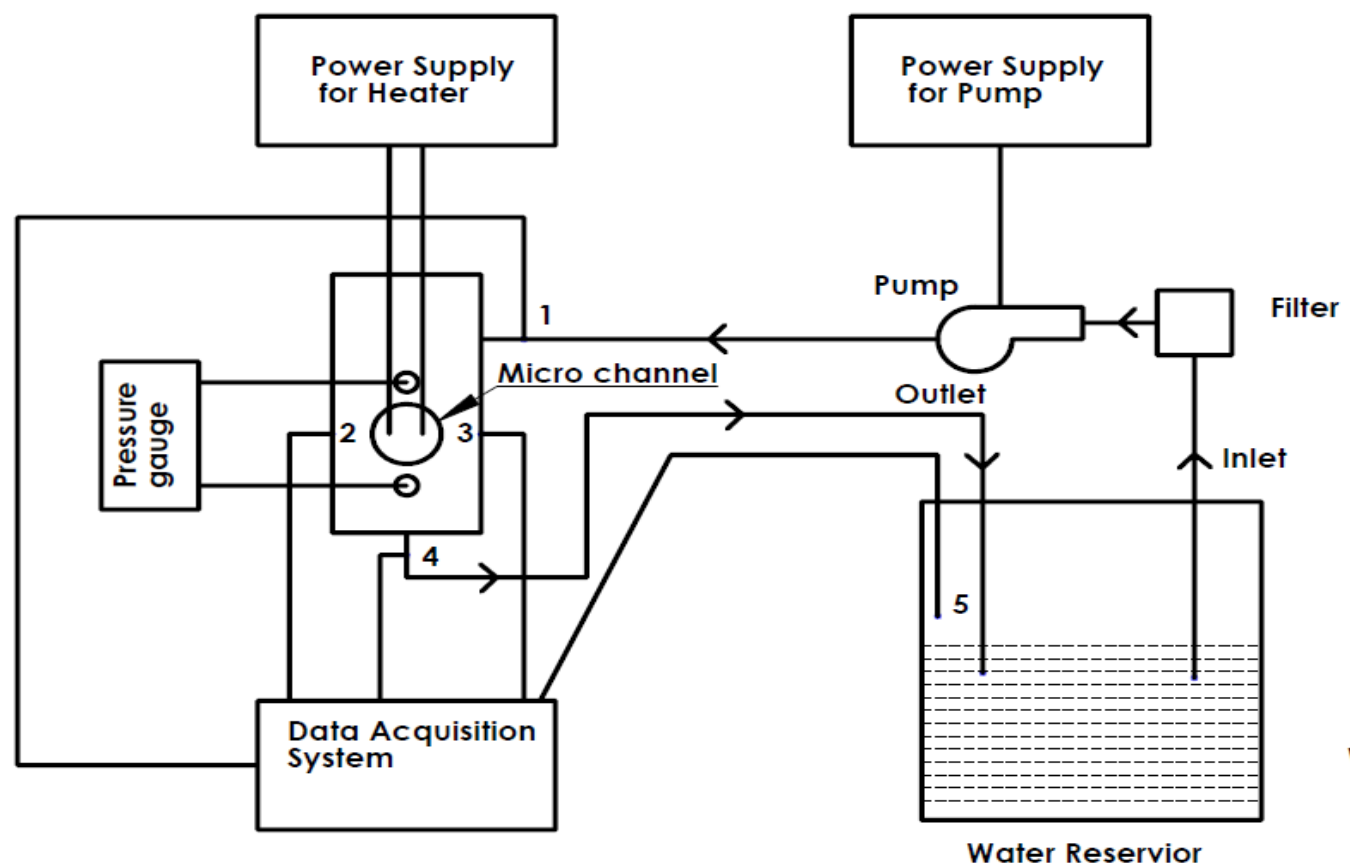

Water

\section{$1,2,3,4,5$ are Thermocouples}

Fig 3: Schematic of experimental setup

\section{SIMULATION}

The micro channel has been modeled \& simulated using the commercial Computational fluid dynamics code ANSYS CFX. In order to minimize the computational load, only half the size of one micro channel has been modeled in three dimensional coordinate taking advantage of the symmetry along the length The model consists of inlet, micro channel region and outlet which is shown as figure 4 .

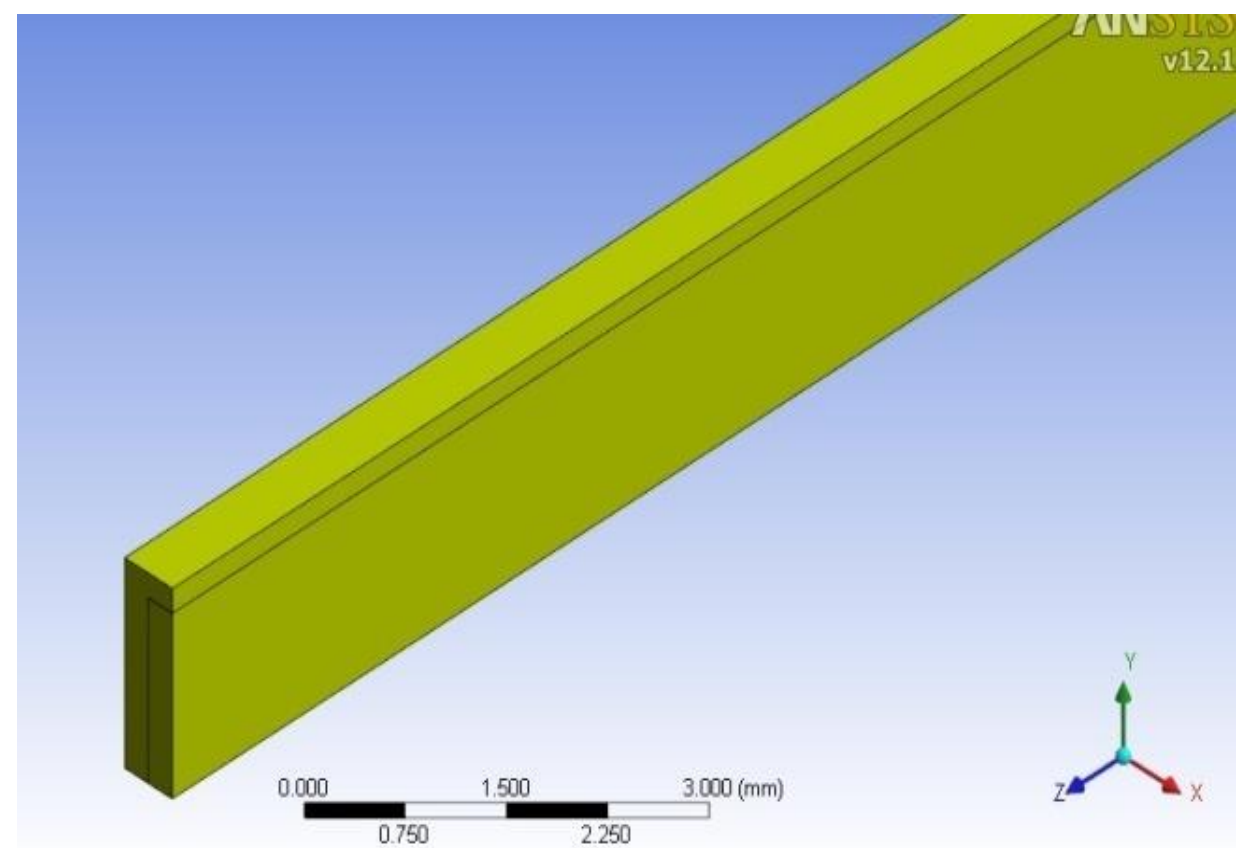

Fig 4: Half Channel CAD Model 


\section{MESH GENERATION}

To ensure the accuracy \& reliability of simulation results it is necessary to carry out the mesh independency of the results. Mesh independency is carried out by varying the cell density on a model for the same set of boundary conditions. ANSYS CFX provides many options to control the mesh density. To ensure grid independent results the model had been meshed at four different levels consisting of 578982, 999592, 1328930 and 2256656 elements. All the solid to fluid interfaces have been inflated to a thickness of 50 micrometers with 8 layers as shown figure 5. The Face spacing of 60 micrometers to 30 micrometers have been applied to fluid region for better resolution. High resolution scheme is selected as the solver option. Double precision has been activated for the improved accuracy. The convergence criterion of $10^{-6}$ is set for residues. Nusselt number from different meshes were in close proximity to each other except the mesh of 578982. The average nusslets number varied by $1.4 \%$ from the first to second mesh level and only by $0.9 \%$ for the second to third meshes level. The fourth mesh level varied by $0.12 \%$ from the third level. Hence a mesh level with 1328930 elements has been chosen for the rest of the analysis as the nusslets number variation is expected to be below $1 \%$.

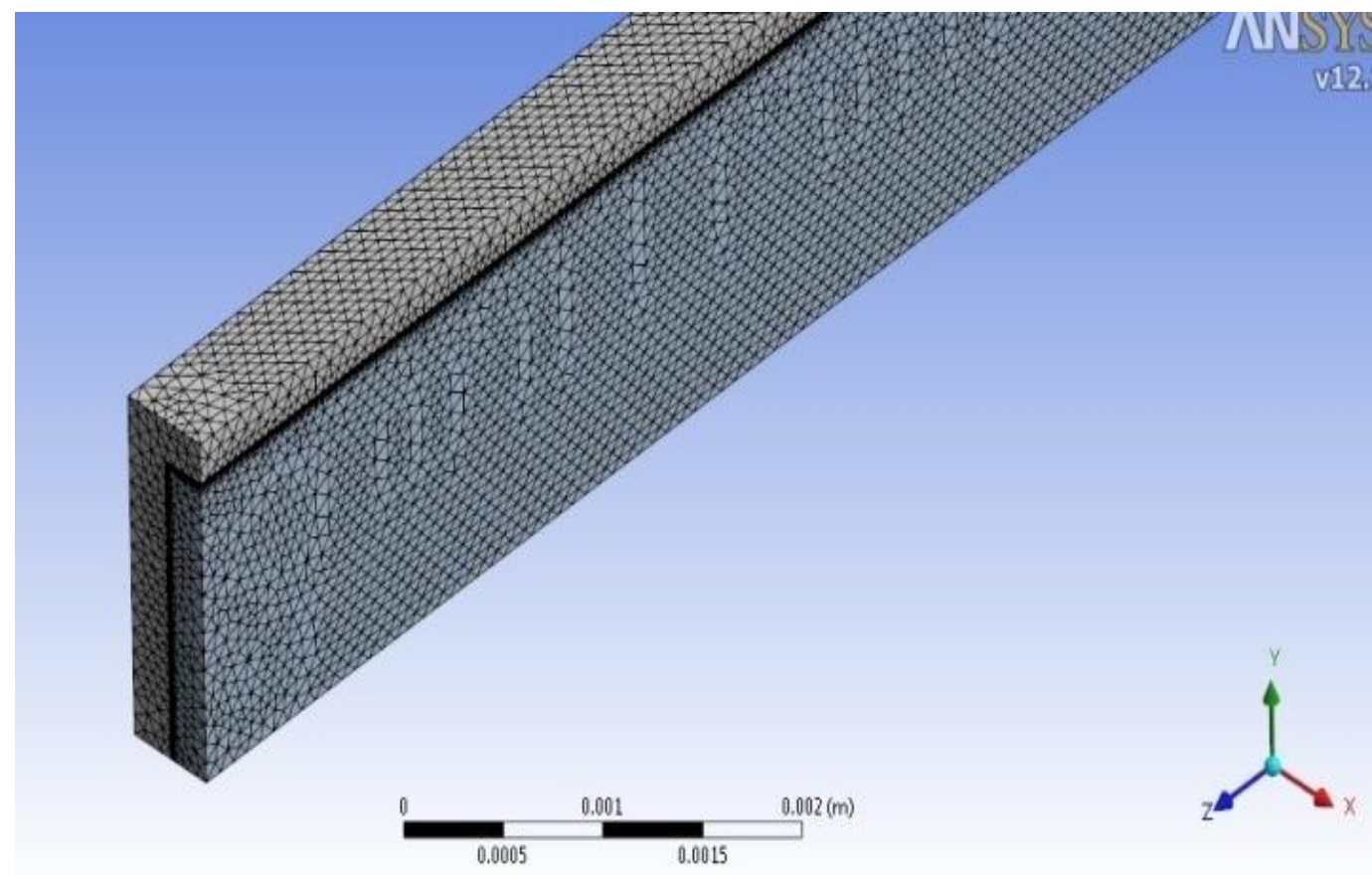

Fig 5: Meshed model with inflated boundary

\section{BOUNDARY CONDITIONS}

Fully developed velocity profile is assigned to the inlet as reported by P S Lee et al [13] since the flow is thermally developing. Periodic boundary condition is assigned to the sides. A uniform heat flux is applied to the heat sink surface at the bottom. The top of the micro channel heat sink is considered to be bonded with adiabatic cover. Pressure boundary condition is assigned to the outlet, where flow reaches atmospheric pressure. The velocity is varied from $0.48 \mathrm{~m} / \mathrm{s}$ to $1.27 \mathrm{~m} / \mathrm{s}$. The Reynolds number ranged from 503 to 1197 . The simulation was carried out for $25 \mathrm{~W}, 50 \mathrm{~W}$, $75 \mathrm{~W}$ and $100 \mathrm{~W}$ of heat loads.

\section{TEMPERATURE DEPENDENT MATERIALS PROPERTIES USING CEL EXPRESSION}

Copper with constant thermal conductivity of $\mathrm{K}_{\mathrm{cu}}=387.6$ $\mathrm{W} / \mathrm{mK}$ is used as the heat sink material. Water with temperature dependent materials properties have been chosen as coolant fluid. The density, specific heat, thermal conductivity and dynamic viscosity of the coolant fluid has been calculated at the mean fluid temperature using following formulae [18]. The mean fluid temperature is the arithmetic mean of average fluid temperature at inlet and average fluid temperature at outlet.

Density $=\frac{a_{o}+a_{1} T+a_{2} T^{2}+a_{3} T^{3}+a_{4} T^{4}+a_{5} T^{5}}{1+b T}$

Where $a_{0}=999.8396, a_{1}=18.22494, a_{2}=-7.92221 \times 10^{-3}, a_{3}=-$ $5.54485 \times 10^{-5}, \quad \mathrm{a}_{4}=1.49756 \times 10^{-7}, \quad \mathrm{a}_{5}=-3.93295 \times 10^{-10}$, $\mathrm{b}=1.81597 \times 10^{-2}, \quad \mathrm{~T}$ is the mean temperature in ${ }^{\circ} \mathrm{C}$

Specific heat $=8958.9-40.535 \mathrm{~T}+0.11243 \mathrm{~T}^{2}-1.0138$ $\times 10^{-4} \mathrm{~T}^{3}$

Thermal conductivity

$$
\begin{aligned}
& =-0.58166+6.3555 \times 10^{-3} \mathrm{~T} \\
& -7.9643 \times 10^{-6} \mathrm{~T}^{2}
\end{aligned}
$$

Dynamic viscosity $=2.414 \times 10^{-5} \times 10^{\frac{(247.8)}{(\mathrm{T}-140)}}$ 
For the specific heat capacity, thermal conductivity and dynamic viscosity, the temperature should have the unit of Kelvin. These material properties have been modeled using CEL commands in CFX pre [19].

\section{RESULTS \& DISCUSSIONS}

\subsection{Validation \& Bench Marking Of Results}

The experimental data Published by PS Lee et al [18] has been used for validation of the results obtained in this work.
PS Lee et al conducted experiment for different flow rates where the Reynolds numbers of the ranged from 350 to 799 . The pressure drop obtained from experiments and simulation were found to closely match with the published data[18] as shown in figure 6. CFD simulation predicts on an average of $3.2 \%$ higher pressure drop than the experimental values.

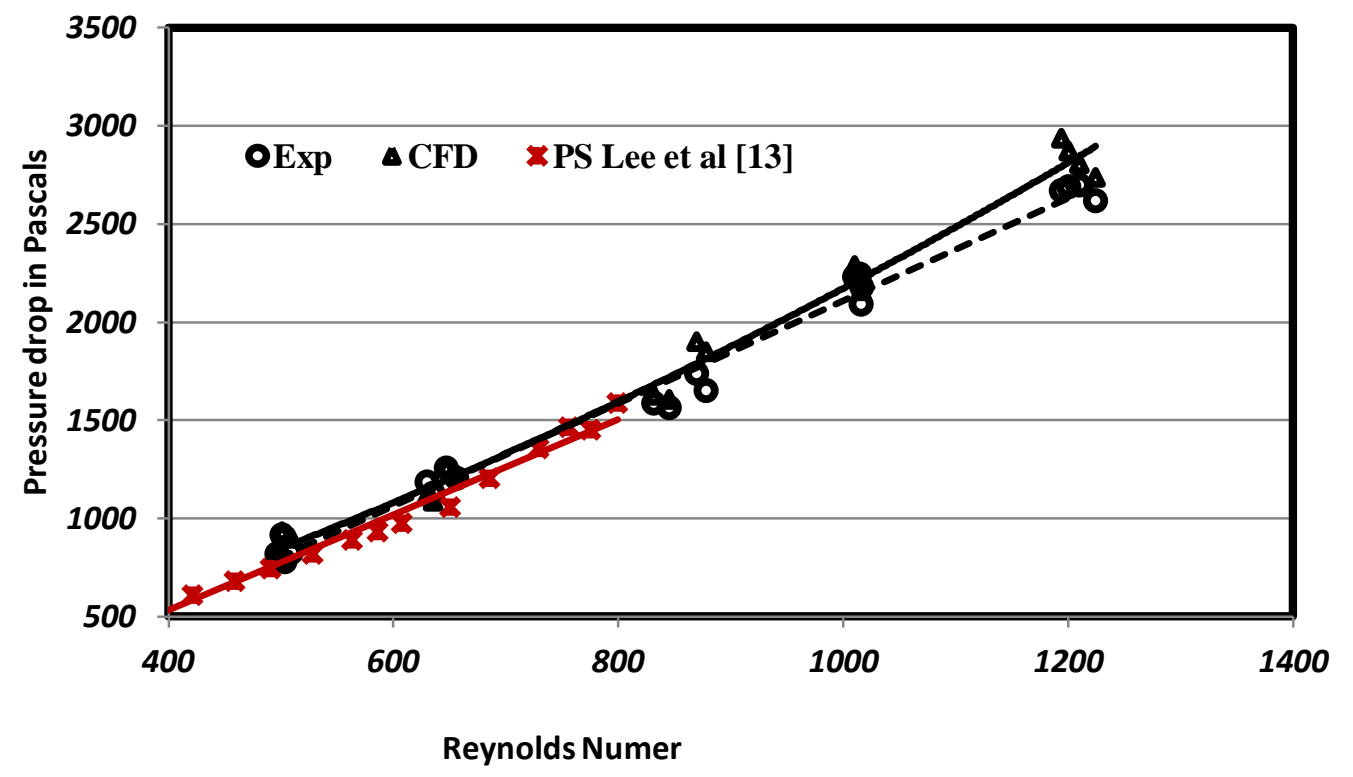

Fig 6: Effect of Fluid flow on Pressure drop

The effect of inlet fluid velocity over the Nusselts number is shown below figure 7. The nusslets number increases as the reynolds number increases. CFD simulation results are closely matching with the experimental and published data.

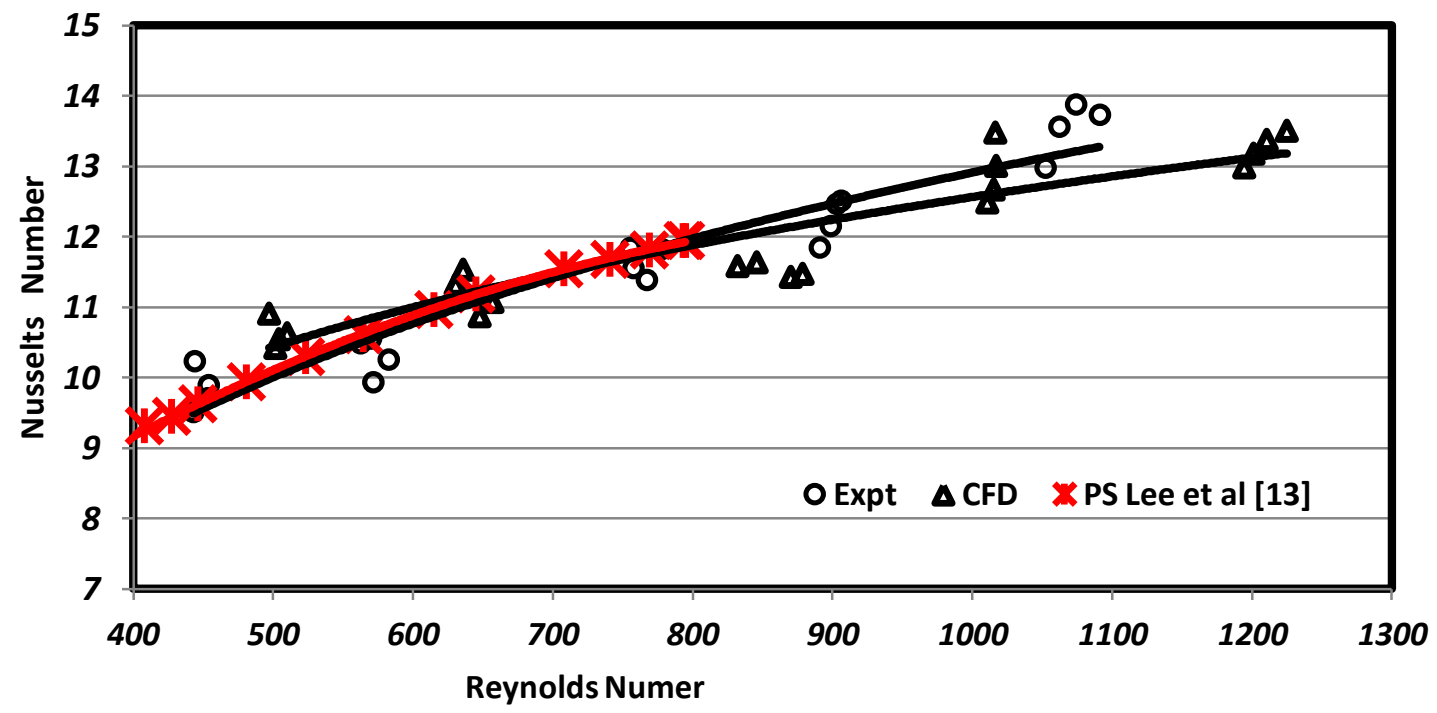

Fig 7: Effect of Reynolds number on the Nusselts Number 


\subsection{Experimental Results}

From the experimental test data, the effect of heat load variation on the pressure drop across the micro channel is shown in figure 8. As the heat load is increased the pressure drop is found to decrease. This can be attributed to the reduction in viscosity with the rise of fluid temperature. The pressure drop is observed to increase with inlet velocity of the fluid as expected.

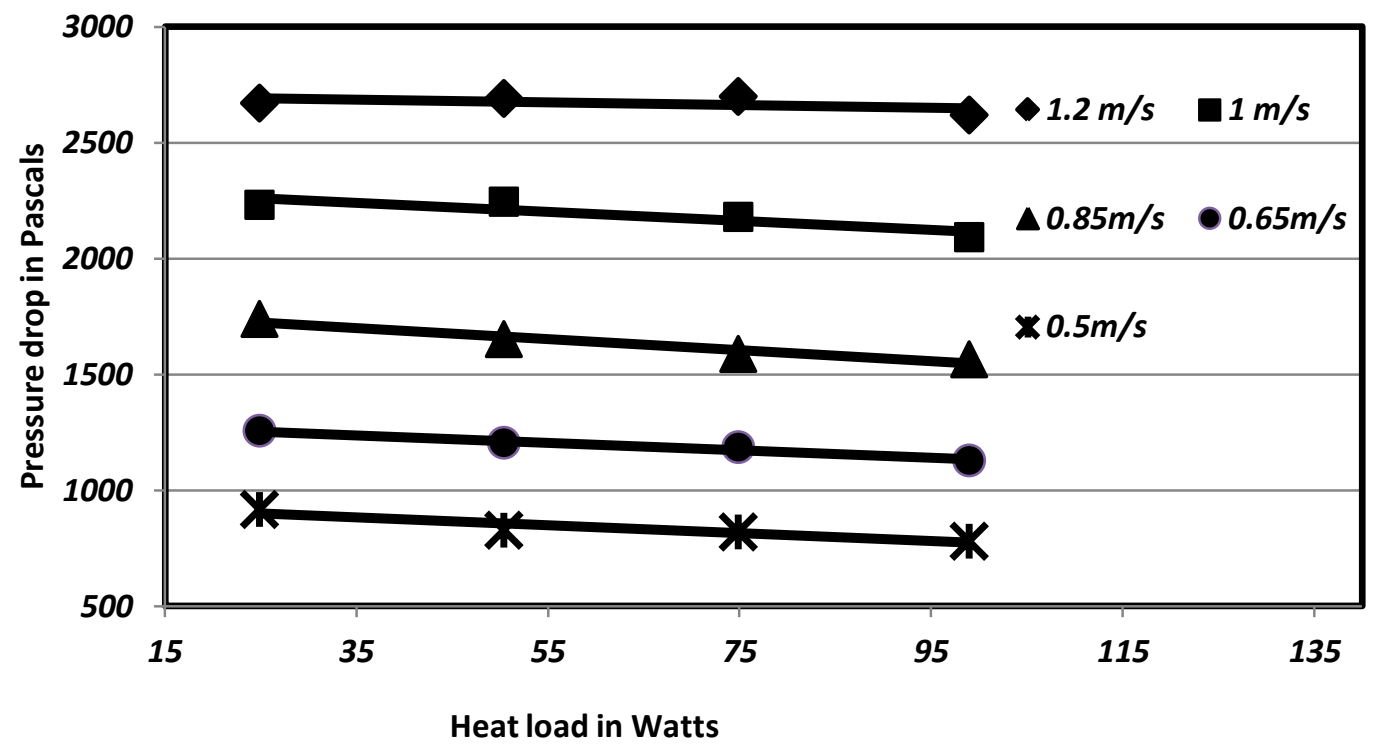

Fig 8: Effect Heat load on the Pressure drop

The variation of mean temperature of the heat sink due to the variation of heat load is shown in figure 9 . It is found that the mean heat sink temperature increases with the increase in the heat load. It is also seen that the mean heat sink temperature reduces as the inlet fluid velocity increases.

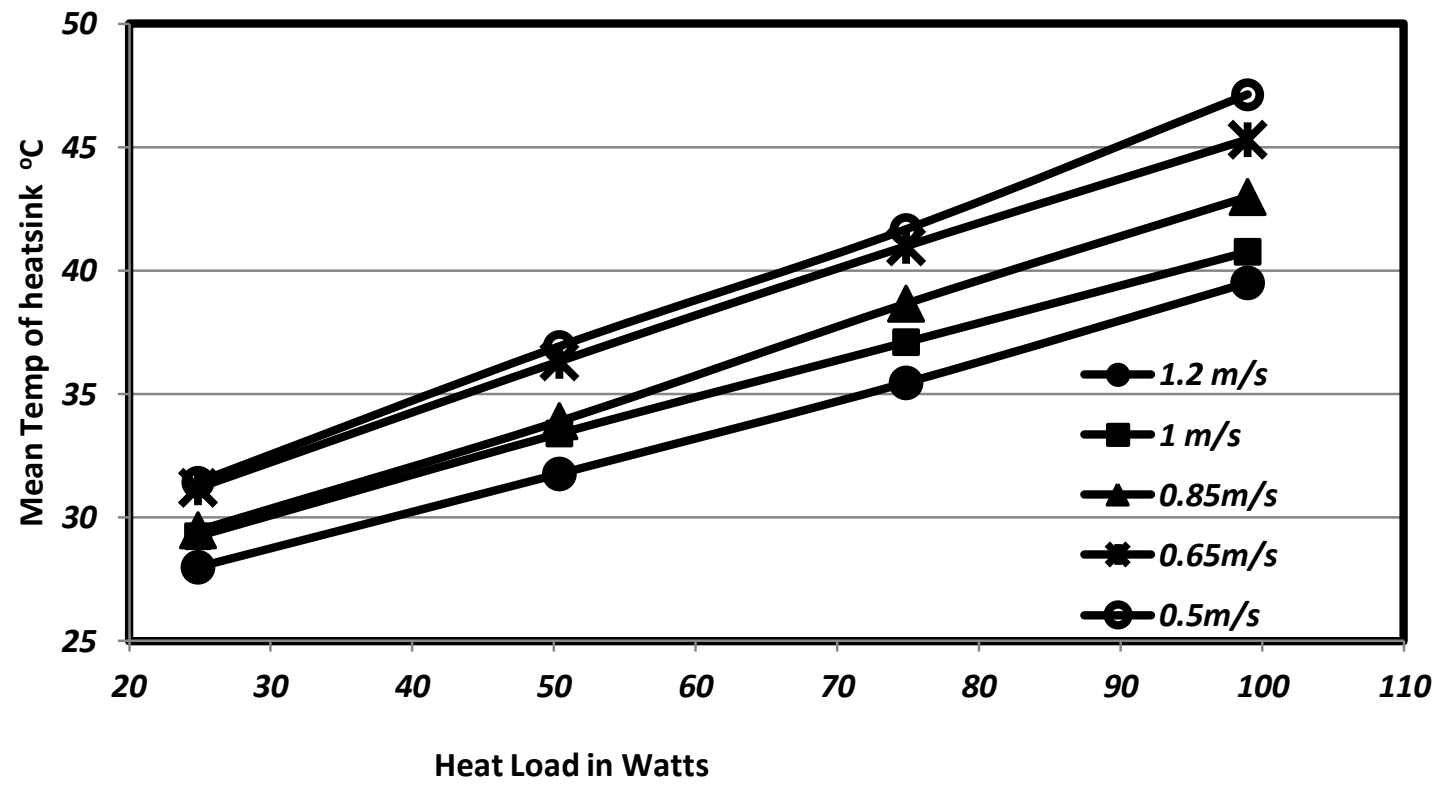

Fig 9: Variation of mean Heatsink temperature with heatload

The variation of friction factor with respect to inlet fluid velocity is shown in figure 10. The variation friction factor predicted by CFD simulation was found to be within $+/-5 \%$ of experimental results 


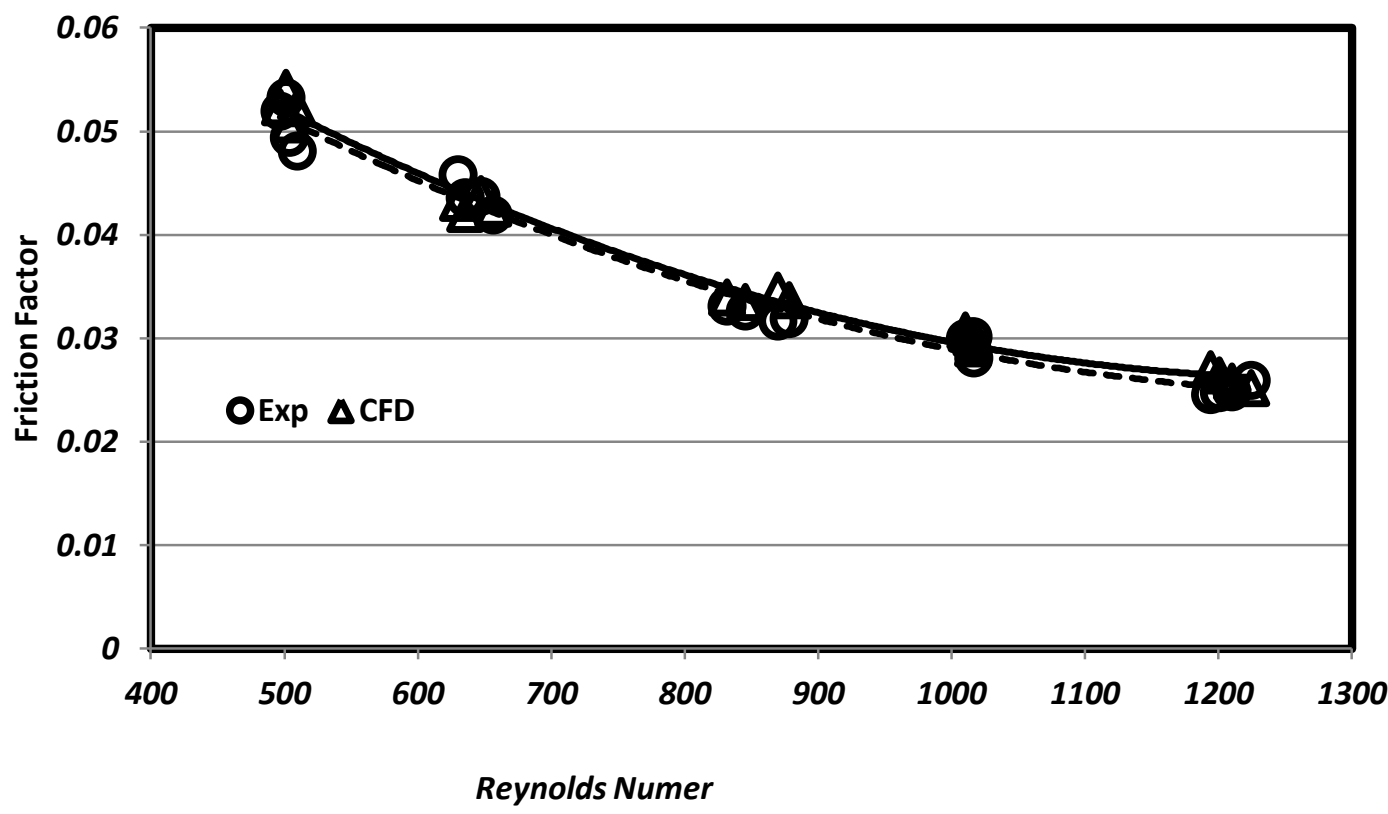

Fig 10: Effect of Reynolds number on friction factor

\section{EFFECT OF TEMPERATURE DEPENDANT MATERIALS PROPERTIES ON SIMULATION}

The effect of temperature dependent material properties on the simulation results was investigated. The results of simulation using Temperature dependent material properties are compared with that of simulation using constant material properties. The variation of pressure drop across the micro channels due to mean fluid temperature was simulated by varying the heat load on the heat sink. The dependence of pressure drop over the mean fluid temperature is depicted in figure 11. The simulation using temperature dependent material properties predicts lesser pressure drop when compared with constant material properties. The pressure drop does not vary for the simulation using constant material properties. The difference is found to be increase as the mean fluid temperature increases. The error in pressure drop prediction is found to increase by $18 \%$ for every 10 degree rise in fluid temperature.

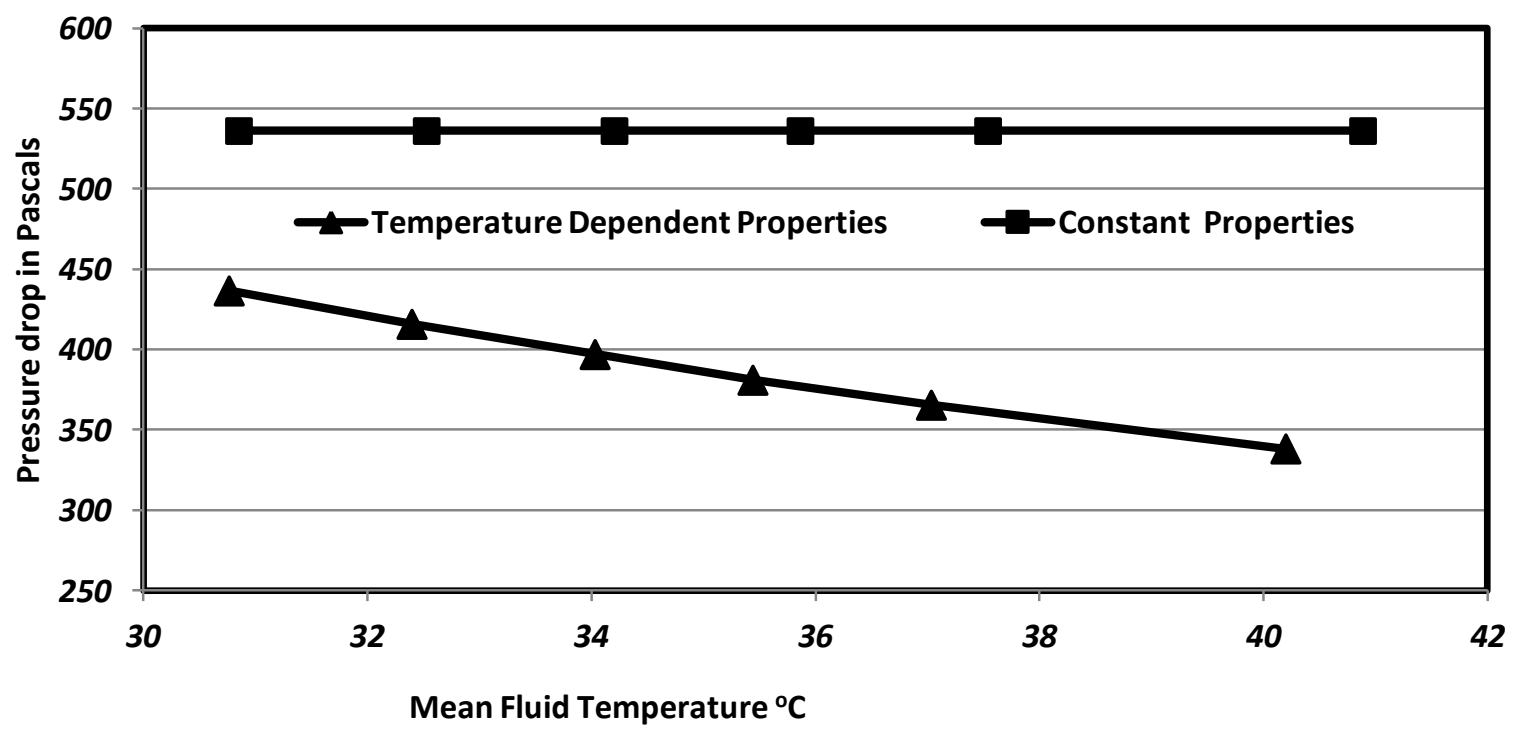

Fig 11: Effect of Fluid Temperature on pressure drop 
The effect of temperature dependant material properties on the dependence of heat transfer coefficient due to mean fluid temperature variation is depicted in figure 12. The heat transfer coefficient rises with the mean fluid temperature for the simulation using temperature dependent material properties. The heat transfer coefficient does not vary for the simulation using constant material properties. The difference is less pronounced when compared that of the pressure drop. The simulation using constant material properties predicts lesser heat transfer coefficient than the simulation using temperature dependent material properties. The heat transfer coefficient is found to increase by $5 \%$ for every 10 degree rise in fluid temperature.

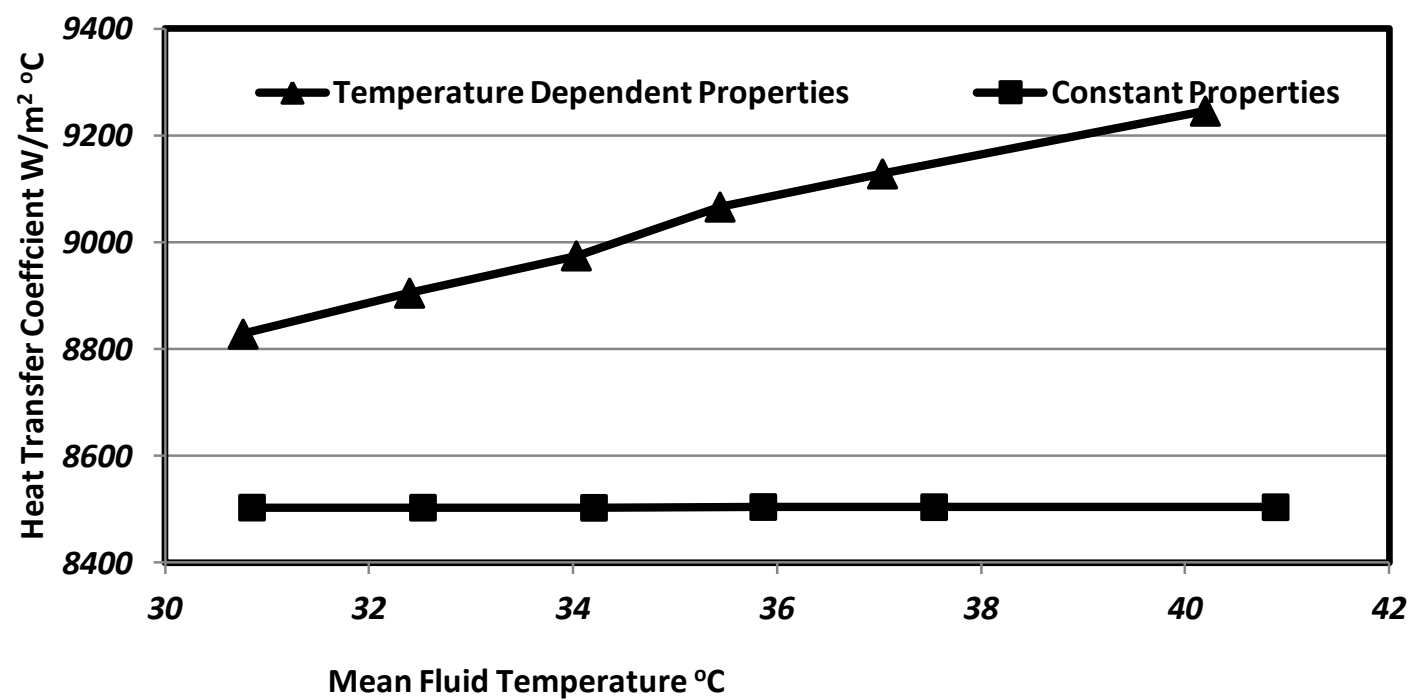

Fig 12: Effect of Fluid Temperature On Heat Transfer Coeffcient

\section{CONCLUSION}

The micro channels have been manufactured on OFHC copper using micro milling. The Experimental \& Numerical studies have been carried out to evaluate the thermal and fluid flow performance of plate fin micro channel heat sink. The micro channel heat sink has been tested for flow rates with inlet velocity ranging $0.48 \mathrm{~m} / \mathrm{s}$ to $1.2 \mathrm{~m} / \mathrm{s}$. From the experimental testing, the nusslets number is found to vary from 10 to 14 for the above range of flow rates. CFD Simulation has been carried out using ANSYS CFX. ANSYS CEL expression is a helpful tool in modeling temperature dependent material properties. The CFD simulation results matched closely with experimental data \& published data. It is important to use temperature dependent material properties in CFD simulation as the temperature dependant material properties influences the accuracy of the results. The simulation using constant material properties predicts $18 \%$ higher pressure drop for every 10 degree rise in the mean fluid temperature and it predicts around 5\% lesser heat transfer coefficient for every 10 degree rise in the mean fluid temperature.

\section{ACKNOWLEDGEMENTS}

The authors acknowledge the support \& encouragement extended by The Director, Microwave tube research \& development center to carry out the work

\section{REFERENCES}

[1]. D. B. Tuckerman and R. F. W. Pease.,1981,"Highperformance heat sinking for VLSI," IEEE Electron Device Lett., vol. EDL-2, no. 5, pp.126-129.

[2]. Sean Ashman \& Satish G kandlikar.,2006, "A Review of Manufacturing process for microchannel heat exchanger fabrication," Proceedings of ASME ICNMM2006,4th International Conference on Nanochannels, Microchannels and Minichannels, Limerick, Ireland.

[3]. A. J. Pang, M.P.Y. Desmulliez, et al., 2004, "Design, Manufacture and Testing of a Low-cost Micro-channel Cooling Device," IEEE Conference on Electronics Packaging Technology.

[4]. Eason, Cormac, Dalton, Tara, O'Mathuna, Cian, Slattery, Orla, Davies, Mark., 2004, "Direct Comparison Between a Variety of Microchannels - Part 1: Channel Manufacture and Measurement,"Second international conference on micro and mini channels.

[5]. R.W. Knight, D.J. Hall, J.S. Goodling, R.C. Jaeger., 1992, 'Heat sink optimization with application to microchannels, ' IEEE Trans. Components, Hybrids, Manufac. Technol. No 15, pp.832-842,

[6]. D.Y. Lee, K. Vafai, Comparative analysis of jet impingement and microchannel cooling for high heat flux applications, Int. J. Heat Mass Transfer, no 42 ,pp 1555$1568,1999$.

[7]. A.Weisberg, H.H. Bau, J.N. Zemel.,1992, “Analysis of microchannels for integrated cooling, Int. J. Heat Mass Transfer,"vol.35, pp.2465-2474.

[8]. Florin Bobaru , Srinivas Rachakonda., 2004,’Optimal shape profiles for cooling fins of high and low 
conductivity," International Journal of Heat and Mass Transfer, no. 47, pp. 4953-4966.

[9]. C.J. Kroeker, H.M. Soliman , S.J. Ormiston, 2004,"Three-dimensional thermal analysis of heat sinks with circular cooling micro-channels," Int. J. Heat Mass Transfer,no. 47, pp. 4733-4744.

[10]. Fanghua Mei, P. R. Parida, Jing Jiang, Wen Jin Meng and Srinath V. Ekkad.,2008,"Fabrication, Assembly, and Testing of $\mathrm{Cu}-$ and Al- based Microchannel Heat Exchangers,"Journal of Microelectromechanical systems, vol.17, no.4.

[11]. Lijubisa D stevanovic et al., 2010,'Integral Microchannel Liquid Cooling for Power Electronics,"'TwentyFifth Annual IEEE, Applied Power Electronics Conference and Exposition (APEC), Palm springs,CA, pp. 1591-1597.

[12]. Ngotan Tran, T. Dang, C. Zhang and Jyh-tong Teng.,2012,"Numerical and experiemental studies on pressure drop and performance index of an aluminium microchannel heatsink,"IEEE International Symposium on computer, consumer and control, Computer (IS3C), Taichung, pp.252-257.

[13]. Poh-Seng Lee, Suresh V. Garimella "Thermally developing flow and heat transfer in rectangular microchannels of different aspect ratios" International Journal of Heat and Mass Transfer 49, 3060-3067,2006

[14]. Y.J.Lee, P.S.Lee, S.K. Chou, "Numerical study of fluid flow and heat transfer in the enhanced microchannel with oblique fins", J. heat transfer,04901-10,vol. 135, April2013

[15]. ANSYS CFX manual v14.5 